\title{
Alexithymia in ankylosing spondylitis
}

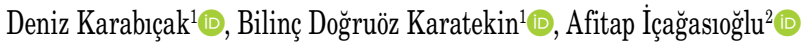 \\ ${ }^{1}$ Department of Physical Medicine and Rehabilitation, Istanbul Medeniyet University Göztepe Training and Research Hospital, Istanbul, Turkey \\ ${ }^{2}$ Department of Physical Medicine and Rehabilitation, Istanbul Medeniyet University Faculty of Medicine, Istanbul, Turkey
}

Received: April 21, 2020 Accepted: December 14, 2020 Published online: September 01, 2021

\begin{abstract}
Objectives: This study aims to determine the effect of ankylosing spondylitis (AS) on alexithymia.

Patients and methods: In this study, a total of 55 AS patients ( 30 males, 25 females; mean age: $40 \pm 8$ years; range, 21 to 57 years) who were under follow-up and 55 age- and sex-matched healthy volunteers ( 31 males, 24 females; mean age: $38.9 \pm 8.5$ years; range, 21 to 53 years) were included between March 2016 and August 2016. Toronto Alexithymia Scale (TAS), and Beck Depression Inventory (BDI) were performed to assess both patient and control groups. The Bath Ankylosing Spondylitis Disease Activity Index (BASDAI), Bath Ankylosing Spondylitis Functional Index (BASFI), Bath Ankylosing Spondylitis Metrology Index (BASMI), and Ankylosing Spondylitis Quality of Life (ASQoL) were performed to assess AS patients.

Results: The mean diagnosis time in the patient group was $5.18 \pm 4.32$ (range, 1 to 18 ) years. Compared to the control group, depression scores were higher in the patient group and the alexithymic characteristics were significantly higher in the patient group ( $\mathrm{p}<0.05$ ). There was a positive correlation between complaint duration and BASMI, BASFI, and ASQoL scores $(\mathrm{p}<0.01)$. In our study, alexithymia rate was significantly higher in women $(\mathrm{p}<0.05)$.

Conclusion: As in all inflammatory chronic diseases, depression and anxiety are commonly seen in AS patients. Alexithymia of these patients should be considered carefully.

Keywords: Alexithymia, Ankylosing Spondylitis Quality of Life, ankylosing spondylitis, Bath Ankylosing Spondylitis Disease Activity Index, Bath Ankylosing Spondylitis Functional Index, Bath Ankylosing Spondylitis Metrology Index.
\end{abstract}

Ankylosing spondylitis (AS) is a rheumatic disease with an unknown etiology, characterized by inflammatory low back pain, often accompanied by peripheral arthritis. Both pain and inflammation in the joints and/or spine have been reported to cause fatigue, sleep disturbance, depression, anxiety, limitations in physical activity, and impaired quality of life (QoL) ${ }^{[1,2]}$ Alexithymia is defined as the problem in identifying, recognizing, distinguishing, and expressing persons' own feeling and others' feelings. The word alexithymia has been coined by "the lack of words to describe feelings". ${ }^{[3]}$ There are many studies showing a close link between depression and alexithymia. ${ }^{[4,5]}$
Several studies have demonstrated that anxiety and depression are common in AS, and impaired QoL is correlated with depression and anxiety levels. ${ }^{[6-8]}$ Since the relationship between chronic diseases and mood changes is known, the relationship between many chronic inflammatory diseases and alexithymia has been investigated in recent years. ${ }^{[9,10]}$ It is important to recognize the frequency of alexithymic features in AS patients, a chronic disease often accompanied by depression, and it is also critical to define the relation of alexithymia with depression in these patients. In the literature, the relationship between many chronic and inflammatory diseases and alexithymia has been investigated. ${ }^{[10-12]}$ However, to the best of our

\footnotetext{
Corresponding author: Bilinç Doğruöz Karatekin, MD. İstanbul Medeniyet Üniversitesi Göztepe Eğitim ve Araştırma Hastanesi, Fiziksel Tip ve Rehabilitasyon Kliniği, 34722 Kadıköy, İstanbul, Türkiye. e-mail: bilincdogruoz@hotmail.com 
knowledge, there are only few studies investigating alexithymia in AS patients. ${ }^{[13,14]}$

Alexithymic features may play a significant role in AS. Difficulty in emotion management may result in physiological distress, thereby, affecting patients' QoL and adherence to therapies adversely. With increasing awareness in diagnosis and treatment of alexithymic features in AS patients, patients may learn to understand and manage their affective status and reflect it to others, which improves their QoL.

In the present study, we aimed to assess the prevalence of alexithymia in AS and determine the relationship between alexithymic features and depression and QoL and disease activity.

\section{PATIENTS AND METHODS}

This cross-sectional study was conducted at Istanbul Medeniyet University, Faculty of Medicine, Department of Physical Medicine and Rehabilitation between March 2016 and August 2016. A total of 55 AS patients ( 30 males, 25 females; mean age: $40 \pm 8$ years; range, 21 to 57 years) who were under follow-up for at least one year and 55 age- and sex-matched healthy volunteers (31 males, 24 females; mean age: $38.9 \pm 8.5$ years; range, 21 to 53 years) were included. The diagnosis of AS was made based on the Assessment of SpondyloArthritis International Society (ASAS) criteria. ${ }^{[15]}$ Patients with fibromyalgia, those aged below 18 years, having visual or hearing impairment, a neurological disease (i.e., cerebrovascular event, multiple sclerosis, or Parkinson's disease), history of a psychiatric disorder (schizophrenia, bipolar disorder), chronic disease (diabetes mellitus, thyroid disease) or malignancy were excluded. A written informed consent was obtained from each participant. The study protocol was approved by the Istanbul Medeniyet University, Health Sciences Ethics Committee (2016/0179). The study was conducted in accordance with the principles of the Declaration of Helsinki.

Demographic and clinical data were recorded for 55 AS patients who were assessed using the Bath Ankylosing Spondylitis Metrology Index (BASMI) for elasticity and spinal mobility, as well as the Bath Ankylosing Spondylitis Functional Index (BASFI) to determine functional status, the Bath Ankylosing Spondylitis Disease Activity Index (BASDAI) to assess the disease activity, and the Ankylosing Spondylitis Quality of Life Questionnaire (ASQoL) to evaluate QoL. ${ }^{[16-18]}$ The Toronto Alexithymia Scale-20 (TAS-20) was used for the assessment of alexithymia which consists of three subscales (TAS-A corresponds to problem in identifying feelings, TAS-B to problem in describing feelings, and TAS-C to externally oriented-thinking). ${ }^{[19]}$ The Beck Depression Inventory (BDI) was used to evaluate depression status of the patients. ${ }^{[20]}$ Alexithymia was evaluated by a physiatrist. Patients with alexithymic features were referred to psychiatry for further evaluation and management.

\section{Statistical analysis}

Statistical analysis was performed using the NCSS version 11.0.16 software (NCSS LLC, Kaysville, UT, USA). Descriptive data were presented in mean \pm standard deviation (SD), median (min-max) or number and frequency, where applicable. For the analyses of the quantitative data, to compare the variables that follow a normal distribution between two groups, the Student t-test was used, while the Mann-Whitney $U$ test was used to compare the variables for non-normally distributed data. Quantitative data were compared using the Pearson's chi-squared test. Pearson $r$ correlation and Spearman rho correlation analyses were used to examine correlations between the variables. The size of the effect was interpreted based on the Cohen's classification where a correlation coefficient between 0.10 and 0.29 indicated a weak association, between 0.30 and 0.49 indicated a moderate association, and between 0.50 and 1.0 indicated a strong association. The $G^{\star}$ Power version 3.1.9.4 software ${ }^{[21]}$ (HeinrichHeine-Universität Düsseldorf, Düsseldorf, Germany) was used for post-hoc power analysis to identify the difference between two independent group means in two-tailed test and the relationship between two variables in the two-tailed test. A $p$ value of $<0.05$ was considered statistically significant.

\section{RESULTS}

Demographic characteristics of the participants are shown in Table 1. There was no statistically significant difference in the age, sex, occupation and education status between the groups ( $p>0.05$ ). However, AS patients had significantly higher body mass index (BMI) values, compared to the controls $(\mathrm{p}<0.05)$.

The AS group scored significantly greater than control subjects on BDI, TAS-20, TAS-A, TAS-B and TAS-C tools $(\mathrm{p}<0.05)$ (Table 2). Female patients found to have markedly higher TAS-20 scores in comparison to male patients although the difference was not significant statistically $(\mathrm{p}>0.05)$. TAS-A scores and TAS-C scores between male and female patients were 


\begin{tabular}{|c|c|c|c|c|c|c|c|c|c|c|c|}
\hline \multicolumn{12}{|c|}{$\begin{array}{c}\text { TABLE } 1 \\
\text { Demographic characteristics of the participants }\end{array}$} \\
\hline & \multicolumn{5}{|c|}{ AS group } & \multicolumn{5}{|c|}{ Control group } & \multirow[b]{2}{*}{$p$} \\
\hline & $\mathrm{n}$ & $\%$ & Mean \pm SD & Median & Min-Max & $\mathrm{n}$ & $\%$ & Mean \pm SD & Median & Min-Max & \\
\hline Age (year) & & & $40.0 \pm 8.0$ & 40.0 & $21-57$ & & & $38.9 \pm 8.5$ & 41.0 & $21-53$ & 0.498 \\
\hline BMI $\left(\mathrm{kg} / \mathrm{m}^{2}\right)$ & & & $27.8 \pm 3.9$ & 26.10 & $19.5-37.0$ & & & $25.3 \pm 3.3$ & 25.07 & $19.5-34.7$ & $0.001^{\star}$ \\
\hline Sex & & & & & & & & & & & 0.850 \\
\hline Female & 25 & 45.5 & & & & 24 & 43.6 & & & & \\
\hline Male & 30 & 54.5 & & & & 31 & 56.4 & & & & \\
\hline Education level & & & & & & & & & & & 0.058 \\
\hline Primary school & 16 & 29.1 & & & & 4 & 7.3 & & & & \\
\hline Secondary school & 14 & 25.5 & & & & 17 & 30.9 & & & & \\
\hline High school & 16 & 29.1 & & & & 27 & 49.1 & & & & \\
\hline University & 9 & 16.4 & & & & 7 & 12.7 & & & & \\
\hline
\end{tabular}

not statistically different ( $\mathrm{p}>0.05)$. However, TAS-B scores of female patients were greater than those of male patients and the difference were statistically significant $(\mathrm{p}<0.05)$.

A positive correlation and a significant association were detected between TAS and BDI scores among patients $(\mathrm{r}=0.369 ; \mathrm{p}<0.01)$. BDI and BASDAI did not show any correlation $(r=0.239 ; p>0.05)$. Correlations of TAS-20, and all subgroup scores with BASDAI,
BASFI, BASMI and ASQoL shown in Table 3. Except BASDAI and TAS-A score, no significant correlations were detected. Also between BASFI and BASDAI scores statistically significant positive correlation was detected $(r=0.661 ; p<0.05)$. Correlations among indices for disease activity and QoL were given in Table 4.

TAS-20 and TAS-A scores were positively correlated with BMI $(p<0.05)$ and age $(p<0.05)$. TAS-C were positively correlated with duration of delayed diagnosis

\begin{tabular}{|c|c|c|c|c|c|c|c|}
\hline \multicolumn{8}{|c|}{$\begin{array}{c}\text { TABLE } 2 \\
\text { BDI, TAS-20, TAS-A, TAS-B and TAS-C scores by groups }\end{array}$} \\
\hline & \multicolumn{3}{|c|}{ AS group $(n=55)$} & \multicolumn{3}{|c|}{ Control group $(n=55)$} & \multirow[b]{2}{*}{$p$} \\
\hline & Mean \pm SD & Median & Min-Max & Mean \pm SD & Median & Min-Max & \\
\hline BDI & $11.7 \pm 6.9$ & 11.0 & $1-31$ & $8.6 \pm 4.8$ & 8.0 & $2-29$ & $0.008^{*} \dagger$ \\
\hline TAS-20 & $52.1 \pm 7.1$ & 52.0 & $31-70$ & $41.5 \pm 5.3$ & 41.0 & $27-53$ & $0.001^{\star} \ddagger$ \\
\hline TAS-A & $15.6 \pm 4.7$ & 15.0 & $8-30$ & $13.1 \pm 2.8$ & 13.0 & $7-21$ & $0.001^{\star} \ddagger$ \\
\hline TAS-B & $12.8 \pm 2.5$ & 13.0 & $6-19$ & $10.7 \pm 2.0$ & 11.0 & $7-15$ & $0.001^{\star} \ddagger$ \\
\hline TAS-C & $23.6 \pm 3.8$ & 24.0 & $14-32$ & $17.9 \pm 2.7$ & 18.0 & $11-27$ & $0.001^{*} \ddagger$ \\
\hline
\end{tabular}

TABLE 3

Correlations of TAS-20, TAS-A, TAS-B and TAS-C scores with BASDAI, BASFI, ASQoL and BASMI scores

\begin{tabular}{|c|c|c|c|c|c|c|c|c|}
\hline & \multicolumn{2}{|c|}{ TAS-20 } & \multicolumn{2}{|c|}{ TAS-A } & \multicolumn{2}{|c|}{ TAS-B } & \multicolumn{2}{|c|}{ TAS-C } \\
\hline & $\mathrm{r}$ & $p$ & $\mathrm{r}$ & $p$ & $\mathrm{r}$ & $p$ & $\mathrm{r}$ & $p$ \\
\hline BASDAI & 0.243 & 0.074 & 0.270 & $0.046^{*}$ & 0.124 & 0.368 & 0.045 & 0.745 \\
\hline BASFI & 0.158 & 0.248 & 0.214 & 0.116 & -0.049 & 0.724 & 0.043 & 0.757 \\
\hline ASQoL & 0.222 & 0.104 & 0.249 & 0.067 & 0.208 & 0.127 & -0.053 & 0.702 \\
\hline BASMI & 0.249 & 0.067 & 0.160 & 0.242 & 0.038 & 0.782 & 0.159 & 0.248 \\
\hline
\end{tabular}

TAS: Toronto Alexithymia Scale; BASDAI: Bath Ankylosing Spondylitis Disease Activity Index; BASFI: Bath Ankylosing Spondylitis Functional Index; ASQoL: Ankylosing Spondylitis Quality of Life Questionnaire; BASMI: Bath Ankylosing Spondylitis Metrology Index; r: Spearman rho Coefficient of Correlation; ${ }^{\star} \mathrm{p}<0.05$. 


\begin{tabular}{|c|c|c|c|c|c|c|}
\hline \multicolumn{7}{|c|}{$\begin{array}{c}\text { TABLE } 4 \\
\text { Correlations among BASDAI, BASFI, ASQoL and BASMI scores }\end{array}$} \\
\hline & \multicolumn{2}{|c|}{ BASFI } & \multicolumn{2}{|c|}{ ASQoL } & \multicolumn{2}{|c|}{ BASMI } \\
\hline & $\mathrm{r}$ & $p$ & $\mathrm{r}$ & $p$ & $\mathrm{r}$ & $p$ \\
\hline BASDAI & 0.661 & $0.001^{\star} \dagger$ & 0.670 & $0.001^{\star} \dagger$ & 0.199 & $0.146 \dagger$ \\
\hline BASFI & 1 & - & 0.675 & $0.001^{\star} \dagger$ & 0.305 & $0.024^{\star} \dagger$ \\
\hline ASQoL & - & - & 1 & - & 0.128 & $0.352 \dagger$ \\
\hline \multicolumn{7}{|c|}{$\begin{array}{l}\text { BASDAI: Bath Ankylosing Spondylitis Disease Activity Index; BASFI: Bath Ankylosing Spondylitis Functional Index; } \\
\text { ASQoL: Ankylosing Spondylitis Quality of Life Questionnaire; BASMI: Bath Ankylosing Spondylitis Metrology Index; dp: } \\
\text { p-value of Pearson Correlation; }{ }^{*} \mathrm{p}<0.05\end{array}$} \\
\hline
\end{tabular}

\begin{tabular}{|c|c|c|c|c|c|c|c|c|}
\hline \multicolumn{9}{|c|}{ Correlations of TAS-20, TAS-A, TAS-B and TAS-C scores } \\
\hline & \multicolumn{2}{|c|}{ TAS-20 } & \multicolumn{2}{|c|}{ TAS-A } & \multicolumn{2}{|c|}{ TAS-B } & \multicolumn{2}{|c|}{ TAS-C } \\
\hline & $\mathrm{r}$ & $p$ & $\mathrm{r}$ & $p$ & $\mathrm{r}$ & $p$ & $\mathrm{r}$ & $p$ \\
\hline Duration of complaints & 0.194 & $0.157 \dagger$ & 0.148 & $0.281 \dagger$ & 0.026 & $0.850 \dagger$ & 0.151 & $0.271 \dagger$ \\
\hline Duration of delayed diagnosis & 0.155 & $0.259 \dagger$ & 0.002 & $0.987 \dagger$ & 0.024 & $0.862 \dagger$ & 0.277 & $0.041^{\star} \dagger$ \\
\hline Age & 0.216 & $0.024^{\star} \ddagger$ & 0.213 & $0.025^{\star} \ddagger$ & 0.119 & $0.217 \ddagger$ & 0.126 & $0.190 \ddagger$ \\
\hline BMI & 0.349 & $0.001^{\star} \ddagger$ & 0.300 & $0.001^{\star} \ddagger$ & 0.114 & $0.234 \ddagger$ & 0.263 & $0.006^{*} \neq$ \\
\hline
\end{tabular}

$(\mathrm{p}<0.05)$ and BMI values $(\mathrm{p}<0.05)$. However TAS-B scores of the patients had no significant associations with any of the parameters (Table 5).

A post hoc power analysis was applied to for two-tailed test, with two equal sized groups of a total sample of 110 participants and alpha of 0.05 . Results showed that the achieved power is 0.76 for BDI and over 0.90 for TAS-20, and all three subgroups (Table 2).

A post hoc power analysis results showed that the achieved power is 0.83 for the correlation between BASDAI and TAS-A (Table 3) and over 0.90 for the correlation between BASDAI and BASFI, BASDAI and ASQQL, ASQQL and BASFI, BASFI and BASMI (Table 4). Also for the correlation between age and TAS-20 the achieved power is 0.63 and for the correlation between age and TAS-A the achieved power is 0.62 , the achieved power is over 0.80 for correlation between TAS-C with duration of delayed diagnosis and BMI and over 0.90 for correlation between BMI with TAS-20 and TAS-A (Table 5).

\section{DISCUSSION}

In AS, inflammation and pain in the spine and joints have been reported to cause limitations in physical activity, fatigue, sleep disturbance, and impaired QoL. ${ }^{[2,22]}$ Increased anxiety and depression have been demonstrated in $\mathrm{AS}^{[6,23-25]}$ Consistent with the literature, significantly increased levels of depression were found in the patients in the current study. In a study by Barlow et al. ${ }^{[26]}$ involving AS patients, nearly one-third of the patients had a high level of symptoms of depression, and female patients reported more depressive symptoms than men. It was also reported that pain was one of the main determinants of depression among females, but it was less important for men. In the present study, however, we did not analyze depression status according to sex due to the inadequate number of female participants.

Individuals with alexithymia experience problems in recognizing their emotions and building communication, and they struggle to recognize and respond to emotions in others. There are no definitive guidelines for diagnosing alexithymia currently, although several scales have been used in routine clinical assessment to evaluate its signs and symptoms. In the present study, we used TAS.

Alexithymic features have been reported in many chronic inflammatory diseases or diseases with chronic pain, which are mostly followed by a physical medicine and rehabilitation specialist. The important task of the physiatrist is to being alert for alexithymia 
and refer these cases to the psychiatry department for further evaluation and management.

Depression is a diagnostic category which is frequently assessed in studies on alexithymia, and alexithymia has been reported to affect the disease severity in depression. ${ }^{[27,28]}$ In a study, Motan and Gençö $z^{[29]}$ showed that the dimensions of alexithymia have different relationships with anxiety and depression, supporting the finding that alexithymia is a multidimensional construct. They also suggested that alexithymia should be taken into account as a discriminating factor between depression and anxiety. In studies, alexithymia was to be closely associated with concurrent depression. Thus, symptoms of depression may play a mediating role between psychiatric morbidity and alexithymia. ${ }^{[30]}$ Alexithymic features and depression were more common in AS patients in the current study. Alexithymic features as difficulty in emotion management may result in physiological distress and this may affect patients QoL and adherence to therapies. Therefore, it is important to recognize and manage these features in patients with AS.

High-sensitivity C-reactive protein (Hs-CRP) is an important marker of disease activity in AS. In Honkapampi et al.'s ${ }^{[31]}$ study, hs-CRP and interleukin- 6 were significantly higher in alexithymic patients, independent of depressive symptoms. Therefore, it may be considered that alexithymia should be investigated as a confounding factor while determining disease activity in AS patients.

In the literature, the link between alexithymia and disease activity in other rheumatic diseases has been investigated. Psoriasis patients with alexithymic features have a higher disease burden ${ }^{[32]}$ and a significant link has been reported between alexithymia and inflammatory and clinical parameters in psoriatic arthritis and rheumatoid arthritis. ${ }^{[11]}$

There is a very limited number of studies examining alexithymia in AS patients. ${ }^{[13]}$ In a study, a comparison was made between AS and control group only with the total TAS-20 scores. Also, only the BASDAI was taken into account for assessment of AS. In contrast, the BASMI, BASFI, and ASQoL scales alongside the BASDAI and the duration of complaints and duration of delayed diagnosis were assessed in the current study. In the aforementioned study by Solmaz et al., ${ }^{[13]}$ alexithymic characteristics were more prevalent in AS patients. Similarly, in this study, alexithymia scores were significantly higher among AS patients, compared to the control group.
Considering the TAS-20 scores in relation to sex, female patients scored higher than male patients. In contrast to Solmaz et al.'s ${ }^{[13]}$ study which reported a correlation between BASDAI and TAS-20 scores, the BASDAI and TAS-20 scores were not significantly correlated in the present study. When the scores from the TAS-20 subscales were examined in this study, a positive correlation was detected between TAS-A and BASDAI scores. Additionally, analyses did not show a positive correlation of TAS-20 with BASMI, BASFI or ASQoL. Also, BDI and BASDAI did not show a positive correlation. This result indicates that difficulty in identifying feelings can be related to disease activity, independent of depression. Therefore, disease activity can be controlled by targeting alexithymic features in treatment.

The QoL of AS patients was evaluated using the ASQoL which is a QoL assessment scale specifically developed for AS. The correlation of the ASQoL with the BASDAI, BASMI, and BASFI was analyzed, revealing that the ASQoL was correlated with the BASFI and BASDAI, but not significantly correlated with the BASMI. In the study of Bodur et al. ${ }^{[33]}$ a strong correlation between BASDAI and ASQoL was found and patients with a higher disease activity as assessed by the BASDAI scored significantly higher on ASQoL, using the data from the Turkish League Against Rheumatism (TLAR). In another study by Yllmaz et al. ${ }^{[34]}$ examining the QoL in AS, a strong correlation was demonstrated between the BASDAI and ASQoL. It is important to establish the factors that affect the QoL in patients with AS. Shibata et al. ${ }^{[35]}$ showed the relationship between chronic pain and alexithymic features, disability, and low life satisfaction.

The average time to diagnosis in AS is eight years and it is known as rheumatic disease diagnosed at the latest. ${ }^{[36]}$ Diagnostic delay is found to be correlated with the BASFI, BASDAI, ASQoL, BASMI, chest expansion, and sacroiliitis grading. ${ }^{[37]}$ Although there are no studies conducted in AS patients, a study including inflammatory bowel disease patients showed that alexithymia was associated with delay in diagnosis and poor clinical outcome. ${ }^{[38]}$

To the best of our knowledge, there is no study in the literature focusing on the relation of alexithymia with the disease duration, duration of delayed diagnosis, sex, BMI, and age in AS patients. In several studies, obesity was found to be related to emotional dysregulation and alexithymia. ${ }^{[39,40]}$ Likewise, in our study, BMI was found to be significantly associated with alexithymia such that patients with greater BMI 
scored higher on TAS-20 scale. Karagöl et al.'s ${ }^{[41]}$ study did not find a correlation between BMI and alexithymia, but age was only weakly correlated with alexithymia. The authors reported that their small sample size precluded drawing a definite conclusion. In our study, alexithymia was found to be more common in female AS patients than males. Likewise, other studies demonstrated that alexithymia was more common in women. ${ }^{[11,42]}$

Limitation of our study is the relatively small sample size. Further researches investigating long-term follow-up of the disease activity and functional status of AS patients with alexithymic features and whether psychiatric support will have a positive effect on these patients are recommended.

In conclusion, as in all inflammatory chronic diseases, depression and anxiety are commonly seen in AS patients. Alexithymia of these patients should be considered carefully. We believe that psychiatric support is as important and necessary as physical approaches in the treatment of AS patients, and psychometric scales should be applied to these patients before and during the treatment.

\section{Declaration of conflicting interests}

The authors declared no conflicts of interest with respect to the authorship and/or publication of this article.

\section{Funding}

The authors received no financial support for the research and/or authorship of this article.

\section{REFERENCES}

1. Jiang Y, Yang M, Lv Q, Qi J, Lin Z, Liao Z, et al. Prevalence of psychological disorders, sleep disturbance and stressful life events and their relationships with disease parameters in Chinese patients with ankylosing spondylitis. Clin Rheumatol 2018;37:407-14.

2. Ward MM. Quality of life in patients with ankylosing spondylitis. Rheum Dis Clin North Am 1998;24:815-27, x.

3. Dereboy İF. Aleksitimi öz bildirim ölçeklerinin psikometrik özellikleri üzerine bir çalışma [Master Thesis], Ankara: Hacettepe Üniversitesi Tip Fakültesi Psikiyatri Anabilim Dalı; 1990.

4. Honkalampi K, Hintikka J, Tanskanen A, Lehtonen J, Viinamäki H. Depression is strongly associated with alexithymia in the general population. J Psychosom Res 2000;48:99-104.

5. Saarijärvi S, Salminen JK, Tamminen T, Aärelä E. Alexithymia in psychiatric consultation-liaison patients. Gen Hosp Psychiatry 1993;15:330-3.

6. Eren I, Şahin M, Cüre E, İnanlı İÇ, Tunç ŞE, Küçük A. Ankilozan spondilit hastalarinda psikiyatrik belirtilerin yetiyitimi ve yaşam kalitesi ile ilişkileri. Nöropsikiyatri Arşivi 2007;44:1-9.
7. Xu X, Shen B, Zhang A, Liu J, Da Z, Liu H, et al. Anxiety and depression correlate with disease and quality-of-life parameters in Chinese patients with ankylosing spondylitis. Patient Prefer Adherence 2016;10:879-85.

8. Baysal O, Durmuş B, Ersoy Y, Altay Z, Senel K, Nas $\mathrm{K}$, et al. Relationship between psychological status and disease activity and quality of life in ankylosing spondylitis. Rheumatol Int 2011;31:795-800.

9. Chimenti MS, Fonti GL, Conigliaro P, Hitaj J, Triggianese P, Teoli M, et al. Evaluation of alexithymia in patients affected by rheumatoid arthritis and psoriatic arthritis: A crosssectional study. Medicine (Baltimore) 2019;98:e13955.

10. Vadacca M, Bruni R, Terminio N, Sambataro G, Margiotta D, Serino FM, et al. Alexithymia, mood states and pain experience in systemic lupus erythematosus and rheumatoid arthritis. Clin Rheumatol 2014;33:1443-50.

11. Chimenti MS, Fonti GL, Conigliaro P, Hitaj J, Triggianese P, Teoli M, et al. Evaluation of alexithymia in patients affected by rheumatoid arthritis and psoriatic arthritis: A crosssectional study. Medicine (Baltimore) 2019;98:e13955.

12. Marchi L, Marzetti F, Orrù G, Lemmetti S, Miccoli M, Ciacchini R, et al. Alexithymia and psychological distress in patients with fibromyalgia and rheumatic disease. Front Psychol 2019;10:1735.

13. Solmaz M, Binbay Z, Cidem M, Sağir S, Karacan İ. Alexithymia and self-esteem in patients with ankylosing spondylitis. Noro Psikiyatr Ars 2014;51:350-4.

14. Yurdakul FG, Garip Çimen Y, Koçak Ulucaköy R, Almaz ŞE, Çalışkan Uçkun A, Bodur H. Impulsivity and ankylosing spondylitis: Is there a relationship? Turk J Phys Med Rehabil 2018;65:51-8.

15. Rudwaleit M, Braun J, Sieper J; Assessment of SpondyloArthritis international Society. ASAS classification criteria for axial spondyloarthritis. Z Rheumatol 2009;68:591-3. German.

16. Yanik B, Gürsel YK, Kutlay S, Ay S, Elhan AH. Adaptation of the Bath Ankylosing Spondylitis Functional Index to the Turkish population, its reliability and validity: Functional assessment in AS. Clin Rheumatol 2005;24:41-7.

17. Akkoc Y, Karatepe AG, Akar S, Kirazli Y, Akkoc N. A Turkish version of the Bath Ankylosing Spondylitis Disease Activity Index: Reliability and validity. Rheumatol Int 2005;25:280-4.

18. Duruöz MT, Doward L, Turan Y, Cerrahoglu L, Yurtkuran $\mathrm{M}$, Calis $\mathrm{M}$, et al. Translation and validation of the Turkish version of the Ankylosing Spondylitis Quality of Life (ASQOL) questionnaire. Rheumatol Int 2013;33:2717-22.

19. Güleç H, Kose S, Yazici M, Çıtak S, Evren C, Borckardt J, et al. The Turkish version of the 20-Item Toronto Alexithymia Scale (TAS-20): Reliability, validity, and factorial structure. Bulletin of Clinical Psychopharmacology 2009;19:214-20.

20. García-Batista ZE, Guerra-Peña K, Cano-Vindel A, Herrera-Martínez SX, Medrano LA. Validity and reliability of the Beck Depression Inventory (BDI-II) in general and hospital population of Dominican Republic. PLoS One 2018;13:e0199750.

21. Faul F, Erdfelder E, Lang AG, Buchner A. G*Power 3: a flexible statistical power analysis program for the social, behavioral, and biomedical sciences. Behav Res Methods 2007;39:175-91. 
22. Geissner E. Psychological factors of pain control and their effects on pain evoking subjective stress. Z Klin Psychol Psychopathol Psychother 1991;39:46-62. German.

23. Karan A, Ozcan E, Aydın R. Ankilozan spondilitli hastaları değerlendirmede kullanılan skalaların karşılaştırılması. Turk J Phys Med Rehabil 1999;2:18-22.

24. Ozgül A, Peker F, Taskaynatan MA, Tan AK, Dinçer K, Kalyon TA. Effect of ankylosing spondylitis on healthrelated quality of life and different aspects of social life in young patients. Clin Rheumatol 2006;25:168-74.

25. Karkucak M, Özden G, Çapkın E, Tosun M, Alaca H, Barçak Ö. Ankilozan spondilitte anksiyete ve depresyon düzeyi, yaşam kalitesini etkileyen faktörler. FÜ Sağ Bil Tip Derg 2010;24:16-9.

26. Barlow JH, Macey SJ, Struthers GR. Gender, depression, and ankylosing spondylitis. Arthritis Care Res 1993;6:45-51.

27. Posse M, Hällström T. Depressive disorders among somatizing patients in primary health care. Acta Psychiatr Scand 1998;98:187-92.

28. Honkalampi K, Hintikka J, Laukkanen E, Lehtonen J, Viinamäki H. Alexithymia and depression: A prospective study of patients with major depressive disorder. Psychosomatics 2001;42:229-34.

29. Motan I, Gençöz T. Aleksitimi boyutlarinin depresyon ve anksiyete belirtileri ile ilişkileri. Turk Psikiyatri Derg 2007;18:333-43.

30. Honkalampi K, Koivumaa-Honkanen H, Lehto SM, Hintikka J, Haatainen K, Rissanen T, et al. Is alexithymia a risk factor for major depression, personality disorder, or alcohol use disorders? A prospective population-based study. J Psychosom Res 2010;68:269-73.

31. Honkalampi K, Lehto SM, Koivumaa-Honkanen $H$, Hintikka J, Niskanen L, Valkonen-Korhonen M, et al. Alexithymia and tissue inflammation. Psychother Psychosom 2011;80:359-64.

32. Sampogna F, Puig L, Spuls P, Girolomoni G, Radtke MA, Kirby B, et al. Prevalence of alexithymia in patients with psoriasis and its association with disease burden: A multicentre observational study. $\mathrm{Br} \mathrm{J}$ Dermatol 2017;176:1195-203.
33. Bodur H, Ataman S, Rezvani A, Buğdaycı DS, Cevik $\mathrm{R}$, Birtane $\mathrm{M}$, et al. Quality of life and related variables in patients with ankylosing spondylitis. Qual Life Res 2011;20:543-9.

34. Yılmaz O, Tutoğlu A, Garip Y, Ozcan E, Bodur H. Healthrelated quality of life in Turkish patients with ankylosing spondylitis: Impact of peripheral involvement on quality of life in terms of disease activity, functional status, severity of pain, and social and emotional functioning. Rheumatol Int 2013;33:1159-63.

35. Shibata M, Ninomiya T, Jensen MP, Anno K, Yonemoto $\mathrm{K}$, Makino S, et al. Alexithymia is associated with greater risk of chronic pain and negative affect and with lower life satisfaction in a general population: The Hisayama Study. PLoS One 2014;9:e90984.

36. Moran SP, Longton C, Bukhari M, Ottewell L. AB0708 Delay to diagnosis in ankylosing spondylitis: a local perspective. Ann Rheum Dis 2016;75:1146-7.

37. Fallahi S, Jamshidi AR. Diagnostic delay in ankylosing spondylitis: Related factors and prognostic outcomes. Arch Rheumatol 2015;31:24-30.

38. Viganò CA, Beltrami MM, Bosi MF, Zanello R, Valtorta M, Maconi G. Alexithymia and psychopathology in patients suffering from inflammatory bowel disease: Arising differences and correlations to tailoring therapeutic strategies. Front Psychiatry 2018;9:324.

39. Casagrande M, Boncompagni I, Forte G, Guarino A, Favieri F. Emotion and overeating behavior: Effects of alexithymia and emotional regulation on overweight and obesity. Eat Weight Disord 2020;25:1333-45.

40. Fernandes J, Ferreira-Santos F, Miller K, Torres S. Emotional processing in obesity: A systematic review and exploratory meta-analysis. Obes Rev 2018;19:111-20.

41. Karagöl A, Özçürümez G, Taşkıntuna N, Nar A. Beden kitle indeksinin depresyon ve aleksitimi ile ilişkisi. Anadolu Psikiyatri Derg 2014;15:207-13.

42. de Barros ACS, Furlan AER, Marques LHN, de Araújo Filho GM. Gender differences in prevalence of psychiatric disorders, levels of alexithymia, and coping strategies in patients with refractory mesial temporal epilepsy and comorbid psychogenic nonepileptic seizures. Epilepsy Behav 2018;82:1-5. 